\title{
Estimating the Poverty Line and Living Conditions of Rural Households: A Case Study
}

\author{
Seyed Abdollah Moosavi ${ }^{1, *}$, Esmaiel Hamid ${ }^{2}$, Sadegh alboali ${ }^{3}$ \\ ${ }^{1}$ Technical and Vocational University, Shohada Ahwaz No 2, Ahwaz, Iran \\ ${ }^{2}$ Department of Accounting, Shadegan Branch, Islamic Azad University, Shadegan, Iran \\ ${ }^{3}$ Department of Accounting, Mahshahr Branch, Islamic Azad University, Mahshahr, Iran \\ *Corresponding author: hamid13561356@gmail.com
}

Received October 28, 2013; Revised November 18, 2013; Accepted December 02, 2013

\begin{abstract}
Poverty has always been studied in a world of certainty. However, if the aim of studying poverty is not only improving the well-being of households who are currently poor, but also preventing people from becoming poor in the future, a new forward looking perspective must be adopted. For thinking about appropriate forwardlooking anti-poverty interventions (i.e. interventions that aim to prevent or reduce future poverty rather than alleviate current poverty), the critical need then is to go beyond a cataloging of who is currently poor and who is not, to an assessment of households' vulnerability to poverty. In this paper, the cost and income of rural households in Khuzestan province have been reviewed and analyzed. Subjective poverty line in terms of behavioral observation were estimated by estimating linear expenditure system (LES) based utility function Stone - Gray and using household budget data (1991-2003) for rural area in Khuzestan province. The product portfolio that were estimated for the minimum wage (poverty line) including food, clothing, housing and health. According to the estimates, the minimum required expenditure for a rural household in Khuzestan province with average household size 9/6 persons in 1991 to 339,182 Rls, and in 1996 was 21,407,484 Rls that in 2009 was equivalent to 4,415,051 Rls.
\end{abstract}

Keywords: poverty, rural households, poverty line, linear expenditure system

Cite This Article: Seyed Abdollah Moosavi, Esmaiel Hamid, and Sadegh alboali, "Estimating the Poverty Line and Living Conditions of Rural Households: A Case Study." Journal of Finance and Economics 1, no. 4 (2013): 112-117. doi: 10.12691/jfe-1-4-8.

\section{Introduction}

Poverty is as a phenomenon that relatively exists in all human societies. The phenomenon of the past and present in different schools is as areas of underdevelopment and corruption, poverty is a clear indication of the economic and social underdevelopment, poverty and health are clearly puts the community at risk. Islam has a strong emphasis on poverty reduction.

Poverty reduction programs are often one of the economic priorities of different countries, including Iran. Hence, the calculation of poverty and the poverty line for urban and rural households measure the poverty gap, calculate the amount of contribution or subsidy, poor identification and evaluation of poverty reduction policies and measures that are necessary to make the foregoing purposes.

One way to understand the living conditions of households, in terms of consumer behavior is in consumer theory. Studies to explain consumer behavior and ability of consumer spending measuring due to price changes can appearance in the whole country or in different geographic areas or to validate such characteristics of socio economic study by individuals or communities. Throughout, the population was divided into geographical division of the authenticity of the results can be more specific regarding the welfare of the inhabitants of that region.

In this paper tried to review and analyze based on the last statistical data of household economic status, household income and expenditure of rural households in Khuzestan province, in the face of poverty in the particular geographic and demographic features. This article is written in five parts. The second part, a review of empirical studies conducted in the fields of fashion and household expenditure and poverty in the world and in the linear expenditure system. The third section is a brief review of research. The fourth section deals with the present experimental results and analysis. The fifth section is devoted to summary and conclusions.

\section{Literature Review}

According to Christiansen and Subbarao [5], understanding vulnerability in any human development strategy in conjunction with. Poverty is crucial, firstly, because vulnerability is an intrinsic aspect of well-being. In evaluating household's well-being, one must not be limited to the household's actual welfare status today, but must also account for the household's prospects for being well in the future, and being well today does not imply 
being well tomorrow [11] and [4]. Secondly, understanding vulnerability is also important from an instrumental perspective.

Because of the many risks household face, they often experience shocks leading to a wide variability in their endowment and income [5].

According to Holzmann and Jorgensen [8], a high percentage of households move into Poverty due to temporary shocks (such as illness or loss of employment) that are reversed just one or two years later. Similarly, many of the people who escape poverty or who are not vulnerable now only succeed in doing so or being so for one or two years before a reverse in their circumstances pushes them back below poverty line which makes then vulnerable. The concept of vulnerability therefore, is dynamic and is broadly an ex-ante or forward looking measure of a household's well being or (lack thereof). The term has been used in a variety of related but different meanings. Chambers [3] defined vulnerability as the exposure to contingencies and stress which is defenseless, meaning a lack of means to cope without damaging loss. The World Development Report 2000/01, defined vulnerability as a likelihood that a shock will result in a decline in well-being. To date, no acceptable definition of, or measurement methodology for vulnerability to poverty has been agreed on. However, as demonstrated in Zhang and Wan [17], most researchers prefer to define vulnerability as the probability of a household or individual falling into poverty in future, i.e. the danger that a socially unacceptable level of wellbeing may materialize in future. This definition is followed in this study.

One of the researches done on poverty is household needs anticipated in Sistan and Bluchestan province by Ali Akbar Khosravi [9]. In this study, using a linear expenditure, the poverty line for rural and urban households is estimated during the period 1983-1996. In addition, consumer spending, the main commodity groups (food, clothing, housing and other goods) is predicted for the years 1998-2006. Elias Naderan. and Saieed. Gholami and Nataj Amiri [13] explored a research on the living conditions of urban poverty in Mazandaran province amidst dark green leaves. In this study, the social and economic characteristics of urban households in Mazandaran province have been analyzed with respect to changes in population characteristics, income, and consumption combined, the percentage of households benefiting from the convenience of living and changes in income distribution for the period of 1990-1996. The results of the poverty line as a linear expenditure system approach based on utility function stone - Gary is estimated, showed that household food basket is the largest. Mahmoud Motevaseli and Saeed Samadi [12] have also studied the economic aspects of poverty reduction policies. This study aims to assess the severity and extent of poverty in the community and opportunities for poverty reduction using data from the Household Budget urban 1982-1997. Office of Economic Parliament has also considered to the household consumption model based on consumer demand during 1955-1993. In this study, used the linear expenditure system, the minimum wage, urban consumer's price, and income capability of commodity groups are calculated on the economy.

\section{Methodology}

One of the major tools in determining the extent of poverty is specifying the poverty line that separates the poor from the non-poor. There are two basic methods for determining the poverty line, the use of different criteria (material) and the definition of life was minimal. Combining these two techniques can also be used. In minimum income method, hypothetical basket of goods and services considered being essential for sustaining life and the money to buy this pool is specified as the minimum income. In this paper, to extract a minimum income used household consumption data and linear expenditure system method. In this way, the demand function of households and the poverty line is obtained using the estimated parameters. In general, demand function can be estimated in two-system single-equation and systematic. It is estimated that the demand functions are consistent with the theory of consumer behavior, must impose constraints on these functions, and these constraints can be noted as Engel constraint, homogeneity constraint and symmetry constraint. Clearly, the demand equation is expressed as a single equation cannot mention all the constraints, while the demand equations are specified as a system of demand equations governing the allocation of expenses between all constraints are of the goods, The simultaneous demand for each commodity with the price of goods is related to other goods and customer income. Hence, in many cases demand equation system can analyze consumer behavior better. System of demand equations involving $\mathrm{n}$ demand equations, as will be shown below.

$$
q_{i}=q_{i}\left(p_{1}, p_{2}, \ldots p_{n}, I\right) \quad i=1,2, \ldots, n
$$

In this regard, the budget constraint represents a complete system of demand equations for such a system in the amounts consumed goods ( $q \mathrm{i}$ ) endogenous variables as a function of the prices of all goods (p i) and income variable (I).

The system can be generally divided into two groups divided by the demand equation:

A - Systems cannot be related to a certain utility function.

B - Systems that can be related to a specific utility function.

The first group, constraints that are appropriate to test the constraints imposed on the parameters that can limit the application of theory to the test. However, the second group is designed to provide some or all the restrictions of demand theory. There are different ways to represent a system of household demand in the economic literature. These methods include the Almost Ideal Demand System (AISD) provided by Deaton, A. and J. Muellbauer. (1980), the Rotedom model provided by Tile and Barton (1995) linear expenditure system provided by Stoon (1954).

Four reasons can be cited for employing a linear expenditure system: First, the interpretation of the parameters of this system is very simple. Secondly, this system is a system which itself makes one of the few limitations of demand theory. Thirdly, the equations are linearly for the variables of price and income. Although the linear expenditure system limitations and supplements its own price capability of the goods does not, however, be considered when whole groups of commodities, this 
system can provide a good approximation of reality. Fourthly, fewer parameters are estimated. In other words, if we apply the system of equations used for $n$ goods, only have $(1-2 n)$ parameters (minus one for the sum of $\beta$ is equal to one.) Estimate and the equations for $n$ goods typically have $n^{2}+2 n$ parameters that $n 2$ parameters for price, $\mathrm{n}$ parameters for income and $\mathrm{n}$ parameters remaining constant is needed, for example, the four items of interest and four single equation is used to estimate the 24 parameters in equation 4. However, using linear expenditure system parameter estimation is only 7 instead of 24 parameters, which makes a major contribution to enhancing the degree of freedom. Linear system derived from a utility function is usually assumed for this purpose, the utility Stone - Grey consider the following:

$$
\begin{aligned}
& U=\sum_{i=1}^{n} \beta_{i} \log \left(q_{i}-\gamma_{i}\right) \quad i=1,2, \ldots, n \\
& 0<\beta_{i}<1, \sum_{i=1}^{n} \beta_{i}=1, \quad\left(q_{i}-\gamma_{i}\right)>0
\end{aligned}
$$

Where $U$ represents the utility index, $\gamma_{i}$ is the minimum wage or less consumption of ith goods and $\beta \mathrm{i}$ shows expenditure share of commodity. Bet $\Sigma_{-}(i=1)^{\wedge} \mathrm{n}$ $\beta \mathrm{i}=1$ in equation (2) to supply the necessary curvature of the indifference curve that ensure strictly quasi-concave utility function. Maximized remembered utility function with respect to budget constraints $\Sigma_{-}(\mathrm{i}=1)^{\wedge} \mathrm{n}$ p_i q_i $=$ $\mathrm{m} \_\mathrm{t}$ are obtained following demand functions.

$$
q_{i}=\gamma_{i}+\frac{\beta_{i}}{p_{i}}\left(m_{t}-\sum_{i=1}^{n} \gamma_{k} p_{k}\right) \quad k=1,2, \ldots, n
$$

Where $m_{t}$ represents the total variable costs. The system of equations (4) indicates that the demand for good i have a function as a function of the price of the goods in the price of other goods and income.

The $m_{t}-\sum_{i=1}^{n} \gamma_{k} p_{k}$ was called upon strictly Quasi-concave the amount of which provide minimum living expenses. If both sides of the system (4) multiple to pi, we will have:

$$
p_{i} q_{i}=p_{i} \gamma_{i}+\beta_{i}\left(m_{t}-\sum_{k=1}^{n} p_{k} \gamma_{k}\right) k=1,2, \ldots, n
$$

Equation (5) provides a system of equations, system of equations in which the expenditure on commodity ith, is a function of all prices and income variables. In equation (5) symbol i $\beta$, as noted above, the share of spending, and that the income (expenses) - for example RLS cent increase expenditure on commodity i am after deducting expenses for at least a few rial will increase. I $\beta$ called the marginal propensity to consume was associated with living beyond as they say $\gamma_{i}$ coefficient represents the minimum salary required to consumer goods, or at least ith have is that consumer spending is spent for this product.

The estimated model as the linear cost system is

$$
p_{i t} q_{i t}=p_{i} \gamma_{i t}+\beta_{i}\left(m_{t}-\sum_{k=1}^{n} p_{k} \gamma_{k}\right)
$$

And i $\beta \gamma_{-} i$ the parameters simultaneously, using a grid of possible values are estimates. Three squares methods (3sls), with full information maximum likelihood (FIML) and seemingly unrelated equations (NSUR) is one of these.

In this study to estimate the system of nonlinear equations (7) through (NSUR) used by software Eviews.4. But the main point is that when estimating the system must arrange the covariance matrix $\Sigma$ can be reversed completely linear estimation problem is not encountered. If we add together the above system of equations, then we have:

$$
\varepsilon_{1 t}+\varepsilon_{2 t}+\varepsilon_{3 t}+\varepsilon_{4 t}=0
$$

Since $\sum_{i=1}^{4} \beta_{i}=1$, therefore, the matrix $\Sigma$ is singular and cannot be reversed, the solution to this problem is simple enough that one of the equations (i.e. equation IV) remove the remaining equations are estimated, then according to $\sum_{i=1}^{4} \beta_{i}=1$ limits the estimated parameters to obtain $4 \beta$ (Abrishami, p.56).

In addition to the initial values for parameter estimation should be considered $\gamma_{i}$ and $\beta$. The starting point for the least amount qit during the study period, and the average share of expenditure $\frac{1}{T} \sum \frac{p_{i t} q_{i t}}{M_{t}} \gamma_{-} \mathrm{i}$ and $\mathrm{i} \beta$ are used as initial values. (Resort Samadi p. 93).

Minimum consumption basket of commodities, in Khuzestan province, according to the statistics letter of 1996, so we have:

$$
\beta_{1, \gamma_{1}}=0 / 047 \quad \beta_{2, \gamma_{2}}=0 / 014 \quad \beta_{3,} \gamma_{3}=0 / 013 \gamma_{4}=0 / 004(3.8)
$$

3 - Income and price elasticities in the linear expenditure system

To obtain the formula of income elasticities of demand equation must be linear expenditure system $q_{i}=\gamma_{i}+\frac{\beta_{i}}{p_{i}}\left(m_{t}-\sum_{k=1}^{n} \gamma_{k} p_{k}\right)$ than we were then derived $\mathrm{mt}$ in this case, we're stretching the formula to get the following formula:

$$
\eta_{i}=\beta_{i} \frac{m_{t}}{p_{i} q_{i}}
$$

Since $\beta \mathrm{i}$ and piqi $\mathrm{mt}$ and they are all positive, so the income elasticity is positive, i.e. $0<$ i . (Quant, p 39). If the formula stretching precious insider for linear expenditures system to get a first order equation $p_{i} q_{i}=p_{i} \gamma_{i}+\beta_{i}\left(m_{t}-\sum p_{k} \gamma_{k}\right)$ of pi derived, the formula price elasticity itself put after arranging to get the following equation:

$$
\mathrm{E}_{\mathrm{ii}}=\left(1-\beta_{\mathrm{i}}\right) \frac{p_{i} \gamma_{i}}{p_{i} q_{i}}-1
$$

In equation (10) is positive if $\gamma_{-} \mathrm{i}$ paving own price elasticity is less than one. Cross-price elasticity formula can also be derived from the equation $q_{i}=\gamma_{i}+\frac{\beta_{i}}{p_{i}}\left(m_{t}-\sum_{k=1}^{n} \gamma_{k} p_{k}\right)$ rate than those in $\mathrm{p} \_\mathrm{k} /$ q_i - to achieve so: 


$$
\frac{\partial q_{i}}{\partial p_{k}}=-\frac{\beta_{i} \gamma_{k}}{p_{i}} \& E_{i i}=\frac{\beta_{i} \gamma_{k} p_{k}}{p_{i} q_{i}}
$$

Equation (11) in the cross-price elasticity formula is linear expenditure system, so that the effect of a percentage change in price $K$ th on the amount of consumption goods has i th suggesting (Quant, p 38).

\section{Results}

After the fourth removal of equation system (7) and the initial starting point for the demand parameters are estimated from the first three groups NSUR way.

$$
\begin{aligned}
& \mathrm{E}_{1}=\mathrm{p}_{1 \mathrm{t}} \mathrm{q}_{1 \mathrm{t}}=\mathrm{p}_{1 \mathrm{t}} \gamma_{1}+\beta_{1}\left(m_{t}-p_{1 t} \gamma_{1}-p_{2 t} \gamma_{2}-p_{3 t} \gamma_{3}-\beta_{4 t} \gamma_{4}\right) \\
& \mathrm{E}_{2}=\mathrm{p}_{2 \mathrm{t}} \mathrm{q}_{2 \mathrm{t}}=\mathrm{p}_{2 \mathrm{t}} \gamma_{2}+\beta_{2}\left(m_{t}-p_{1 t} \gamma_{1}-p_{2 t} \gamma_{2}-p_{3 t} \gamma_{3}-\beta_{4 t} \gamma_{4}\right) \\
& \mathrm{E}_{3}=\mathrm{p}_{3 \mathrm{t}} \mathrm{q}_{3 \mathrm{t}}=\mathrm{p}_{3 \mathrm{t}} \gamma_{3}+\beta_{3}\left(m_{t}-p_{1 t} \gamma_{1}-p_{2 t} \gamma_{2}-p_{3 t} \gamma_{3}-\beta_{4 t} \gamma_{4}\right) \\
& \mathrm{E}_{4}=\mathrm{p}_{4 \mathrm{t}} \mathrm{q}_{4 \mathrm{t}}=\mathrm{p}_{4 \mathrm{t}} \gamma_{4}+\beta_{4}\left(m_{t}-p_{1 t} \gamma_{1}-p_{2 t} \gamma_{2}-p_{3 t} \gamma_{3}-\beta_{4 t} \gamma_{4}\right)
\end{aligned}
$$

According to estimates, the coefficient of determination adjusted $99 / 0=\mathrm{R}^{-} 2$ shows that 99 percent of changes in cost of goods $i$ th by the index of prices of a basket of commodity consumption (food, shelter, clothing, health) and spending the entire $\mathrm{mt}$ can be explained by the analyze power is very high. $\mathrm{T}$ statistics estimated coefficients indicate significance at the $95 \%$ confidence coefficient. However, the data used in this study are not expected to impact the income of a household's spending, household spending will affect others, but the statistics earlier estimates of the existence of Dorbin Watson between sentences disrupting the model. Hence, the autocorrelation of a process to meet its first description (1) AR was added to the system.

Table 1. Estimated parameters of the model for rural province 19912009

\begin{tabular}{|c|c|c|c|c|}
\hline $\begin{array}{c}\text { Hygiene } \\
\text { and health }\end{array}$ & $\begin{array}{c}\text { Clothes } \\
\text { and shoes }\end{array}$ & $\begin{array}{c}\text { Housing, } \\
\text { fuel and } \\
\text { utilities }\end{array}$ & $\begin{array}{c}\text { Food and } \\
\text { beverage and } \\
\text { tobacco }\end{array}$ & Parameters \\
\hline $0 / 070$ & $\begin{array}{c}0 / 130 \\
(14 / 432)\end{array}$ & $\begin{array}{c}0 / 214 \\
(14 / 806)\end{array}$ & $\begin{array}{c}0 / 586 \\
(90 / 052)\end{array}$ & $\begin{array}{c}\text { Bi } \\
\text { (statistic t) }\end{array}$ \\
\hline 392 & $\begin{array}{c}1485 \\
(2 / 571)\end{array}$ & $\begin{array}{c}3006 \\
(3 / 098)\end{array}$ & $\begin{array}{c}6270 \\
(2 / 832)\end{array}$ & $\begin{array}{c}\gamma_{\mathrm{i}} \\
\text { (statistic t) }\end{array}$ \\
\hline
\end{tabular}

According to given the constraints $\sum_{i=1}^{4} \beta_{i}=1 \beta 4$ value can be achieved:

$$
0 / 586+0 / 214+\beta 4=1 \beta 4=0 / 07
$$

Price capability of expenditure $\beta i$ implies that if spending beyond subsistence rural families an average of 100 riyals to increase the amount of $6 / 58$ riyal spent on food and beverages, 4/21 riyal spent on housing, 13 rials spent apparel and 7 rials will be spent on healthcare. In other words, $(80=4 / 21+6 / 58)$ percent of rural families living in the province were trained to feed and clothe the most essential needs of life, and only 20 percent is allocated for other purposes remains.
Table 2. Poverty line in the rural area of Khuzestan province

\begin{tabular}{|c|c|c|}
\hline Annual poverty line (RLS) & Monthly poverty line (RLS) & Year \\
\hline $339182 / 2$ & $282665 / 183$ & 1991 \\
\hline $397291 / 58$ & $33107 / 631$ & 1992 \\
\hline $513306 / 88$ & $42775 / 573$ & 1993 \\
\hline $769494 / 92$ & $64124 / 576$ & 1994 \\
\hline 1112600 & $927716 / 666$ & 1995 \\
\hline $2140748 / 4$ & $178395 / 7$ & 1996 \\
\hline $1704993 / 3$ & $142082 / 8$ & 1997 \\
\hline $2213306 / 2$ & $184442 / 18$ & 1998 \\
\hline $2754916 / 9$ & $229576 / 4$ & 1999 \\
\hline $2781367 / 4$ & $2311780 / 61$ & 2000 \\
\hline $3917481 / 8$ & $326456 / 81$ & 2001 \\
\hline $4756193 / 2$ & $396349 / 43$ & 2002 \\
\hline $4415051 / 4$ & $367920 / 95$ & 2003 \\
\hline 17763569 & 1480297 & 2004 \\
\hline 20215717 & 1684643 & 2005 \\
\hline 22706560 & 1892213 & 2006 \\
\hline 26943684 & 2245307 & 2007 \\
\hline 33775086 & 2814590 & 2008 \\
\hline 44164773 & 3680398 & 2009 \\
\hline
\end{tabular}

Source: Estimation Results

In Table 2 the poverty line, the minimum income required to meet the needs of rural households living in Khuzestan between the years 1991-2009 in 1995 constant prices are presented annually and monthly. The estimated minimum spending requirement - the subjective poverty line in a rural household in Khuzestan province in 1991 was at an annual average of 339,182 Rls and 28,265 Rls a month. In 2009 the figure rose to 44,164,773 Rls a month to $3,680,398$ Rls. According to the share of households earn less than the average total household consumption expenditure in the two years from 17.7 percent to 61 percent increase, the inflationary pressures of increasing the level of living of households, despite adjustment households forced to pattern themselves have imposed a minimum cost to live in a rural community in Khuzestan increased from 28,265 Rials per month in 1991 to 3,680,398 Rls . A minimum subsistence groups share food, shoes and clothing, household income of at least demonstrating that the parasite index of household portfolio composition is, on average, the study shows that more than 83 percent of the province of minimum wage expenditures basket the group is dedicated to food and clothing. This shows the importance and high priority to the basic needs of life is less than 20 percent of total household subsistence expenses will be allocated to other commodity groups. Values estimated marginal propensity to pay strictly Quasi-concave costs ( $\beta \mathrm{i})$ suggests that any increase in the income of rural households increased income beyond subsistence Khuzestan which will have the greatest impact in the first place the cost of food. In this context, the cost of food, clothing and health care are secondary priorities.

Table 3 presented the cost of strictly Quasi-concave for households in rural areas of Khuzestan province during 1991-2009. It is estimated that the demand function, the expenses have to be spent on commodity ith, is split into two components: First, the minimum and necessary expenses that must be spent for goods (i.e. $p_{-} i_{\gamma} \gamma_{-}$) and other expenses that represent expenses that are living beyond their authority on the i th consumer goods. 
Table 3. Spending Ultra livelihood expense in Khuzestan province

\begin{tabular}{|c|c|c|c|}
\hline Total expenses (RLS) & Minimum salary (RLS) & strictly Quasi-concave expenses (RLS) & Year \\
\hline 1917170 & $339182 / 2$ & $1577987 / 8$ & 1991 \\
\hline 2716841 & $397291 / 58$ & $2319549 / 5$ & 1992 \\
\hline 3391506 & $513306 / 88$ & $2878199 / 2$ & 1993 \\
\hline 3444933 & $769494 / 92$ & $2675438 / 1$ & 1994 \\
\hline 6885662 & 1112600 & 5773062 & 1995 \\
\hline 7667516 & $2140748 / 4$ & $5526767 / 6$ & 1996 \\
\hline 8666600 & $1704993 / 6$ & $6961606 / 4$ & 1997 \\
\hline 10161871 & $2213306 / 2$ & 7948565 & 1998 \\
\hline 11062218 & $2754916 / 9$ & 8311302 & 1999 \\
\hline 13526616 & $2781367 / 4$ & 10745249 & 2000 \\
\hline 14886617 & $3917481 / 8$ & 1096136 & 2001 \\
\hline 18683495 & $4756193 / 2$ & 13927302 & 2002 \\
\hline 21259289 & $4415051 / 4$ & 1684238 & 2003 \\
\hline 35366689 & 17763569 & 17603120 & 2004 \\
\hline 39574870 & 20215717 & 19359153 & 2005 \\
\hline 45021919 & 22706560 & 22315359 & 2006 \\
\hline 53075732 & 26943684 & 26132048 & 2007 \\
\hline 67574290 & 33775086 & 33799204 & 2008 \\
\hline 71989373 & 44164773 & 27824600 & 2009 \\
\hline
\end{tabular}

Source: Estimation Results

Considering the results presented in Table 3, upon the income of rural households living in Khuzestan, has been growing each year during the studied period, the trend shows that the rural consumer spending Khuzestan during the movie as mere commodities 1991-2003 is different and has grown significantly. The relative improvement of the welfare of rural households defined basket of goods according to the story. This result is not in any way mean that this group of consumers is in good condition.

Notes to Table 3 came to a steep drop in Khuzestan strictly Quasi-concave rural families in 2001 and 116 percent growth over the past two consecutive years noted 1994 and 1995.

\subsection{Estimated Price and Income Elasticities}

Using estimates of the share of expenditure $(\beta \mathrm{i})$ and related $\eta_{i}=\beta_{i} \frac{m_{t}}{p_{i} q_{i}}$, income capability for a basket of goods has been calculated in Table 4 .

Table 4. Estimation of income elasticities (total expenditure) Commodity groups living in the rural household of Khuzestan province

\begin{tabular}{|c|c|c|c|c|}
\hline Hygiene and health & Clothes and shoes & Housing, fuel and utilities & Food and beverage & Goods group \\
\hline $1 / 11$ & $0 / 99$ & $0 / 97$ & $1 / 04$ & Income capability \\
\hline 628312 & 1321965 & 2057210 & 5552169 & Average annual expenditure (RLS) \\
\hline
\end{tabular}

Source: Estimation Results

Income elasticities in Table 4 based on the average expenditure on each item and the total average costs are calculated in 1991-2003.

If strictly Quasi-concave income increases by $10 \%$ for a rural household stretch who can say that the demand for feed increases 4/10 percent, to accommodate 7/9 per cent, to clothing 9/9 percent for health 1/11respectively. Increase rural incomes above the demand for housing, food, and next time it rises. Because of the high share of consumer spending on food and clothing to the total cost of goods considered, because the study was on average $80 \%$ of the household expenditure spent on food, clothing is a rural household in Khuzestan province. If we assume $10 \%$ of the rural livelihood extra income decreases, the maximum damage inflicted on the consumer group food and clothing. Using the estimated share of the costs of trans-living $(\beta \mathrm{i})$ and estimates the minimum spending requirement $\left(\gamma_{-} \mathrm{i} s\right)$, price elasticities own cross and calculated (Table 5) was the calculation of price elasticities and cross respectively the $E_{i i}=\left(1-\beta_{i}\right) \frac{p_{i} \gamma_{i}}{p_{i} q_{i}}-1$ and $E_{i k}=-\frac{\beta_{i} \gamma_{k} p_{k}}{p_{i} q_{i}}$ is used.

Table 5. Own and cross-price elasticities for different commodity groups, rural household of Khuzestan province 1991-2009

\begin{tabular}{|c|c|c|c|c|}
\hline $\begin{array}{c}\text { Hygiene } \\
\text { and health }\end{array}$ & $\begin{array}{c}\text { Clothes } \\
\text { and shoes }\end{array}$ & $\begin{array}{c}\text { Housing, } \\
\text { fuel and } \\
\text { utilities }\end{array}$ & $\begin{array}{c}\text { Food and } \\
\text { beverage }\end{array}$ & Goods group \\
\hline$-0 / 07$ & $-0 / 11$ & $-0 / 39$ & $-0 / 57$ & $\begin{array}{c}\text { Food and } \\
\text { beverage }\end{array}$ \\
\hline$-0 / 06$ & $-0 / 09$ & $-0 / 48$ & $-0 / 56$ & $\begin{array}{c}\text { Housing, } \\
\text { fuel and } \\
\text { utilities }\end{array}$ \\
\hline$-0 / 06$ & $-0 / 45$ & $-0 / 32$ & $-0 / 54$ & $\begin{array}{c}\text { Clothes and } \\
\text { shoes }\end{array}$ \\
\hline$-0 / 06$ & $-0 / 12$ & $-0 / 43$ & $-0 / 070$ & $\begin{array}{c}\text { Hygiene and } \\
\text { health }\end{array}$ \\
\hline
\end{tabular}

Source: Estimation Results

Own and cross-price capability in Table 5 based on average minimum salary and average expenditure on each commodity is calculated. Goods of the lowest own price elasticity belonging to the maximum Product Group Health and food is a commodity groups. The food price index increased by $10 \%$, demand for housing, $9 / 3 \%$ and Health 7/0 percent decline. 


\section{Appendix}

Estimated minimum expenditure necessary in rural households of Khuzestan province

\begin{tabular}{|c|c|c|c|c|}
\hline Foods & Housing & Clothes & Health & Year \\
\hline 185216 & 108396 & 35954 & 9616 & 1991 \\
\hline 213055 & 129138 & 38927 & 16127 & 1992 \\
\hline 375113 & 170711 & 47210 & 20070 & 1993 \\
\hline 452067 & 206783 & 77843 & 3203 & 1994 \\
\hline 627000 & 300600 & 145800 & 39200 & 1995 \\
\hline 758983 & 407914 & 186842 & 55056 & 1996 \\
\hline 890967 & 515228 & 227885 & 70913 & 1997 \\
\hline 6201332 & 655909 & 273667 & 82398 & 1998 \\
\hline 1535523 & 765787 & 318464 & 135152 & 1999 \\
\hline 1549819 & 812221 & 320614 & 98713 & 2000 \\
\hline 2225223 & 1037070 & 428652 & 226537 & 2001 \\
\hline 2741224 & 1248091 & 489596 & 227262 & 2002 \\
\hline 2320527 & 12877704 & 490763 & 315991 & 2003 \\
\hline 6408252 & 2100360 & 2377021 & 2223629 & 2004 \\
\hline 7220092 & 2337454 & 2670078 & 2541740 & 2005 \\
\hline 8569956 & 2482122 & 2823310 & 2910875 & 2006 \\
\hline 10784502 & 2845130 & 3158507 & 3385207 & 2007 \\
\hline 14243229 & 3506851 & 3687159 & 4168832 & 2008 \\
\hline 21328815 & 4109633 & 4336482 & 5005370 & 2009 \\
\hline$S 04 r: E s m$ & & & \\
\hline
\end{tabular}

Source: Estimation Results

\section{References}

[1] Abrishami, Hamid( 2002) Applied Econometrics, Tehran, Tehran University Press, 2002.

[2] Center of economic ups and downs in the last 30 years spending, parliamentarians and research sixth year, in February and March 1998, pp. 81-91.

[3] Chambers, R. (1989). Vulnerability, coping and policy. Institute of Development Studies Bulletin, 20(2):1-7.
[4] Chaudhuri, S., Jalan, J. and A. Suryahadi. (2002). Assessing Household Vulnerability to poverty from cross-sectional data. A methodology and estimates from Indonesia, Discussion paper No. 0102-52. New York: Columbia University.

[5] Christianensen, L. J and K. Subbarao. (2005). Towards an understanding of vulnerability in Rural Kenya. Journal of African Economies, 14(4): 520-58.

[6] Gamaletsos T. , Andrik opoulos, A .Brox, J.A, (1984) Forecasting candian consumption using the Dynamic Generalized linear Expenditure system Applid Economics, Vol 16, No 36,PP.

[7] James. M. and Richard Henderson. A. Kvant (2002), microeconomic theory, Tehran, Press Institute of Cultural Services Rasa, 2002.

[8] Holzmann, R, and Jorgensen, S. (1999): Social Protection as Social Risk Management: Conceptual Underpinnings for the Social Protection Sector Strategy Paper, Journal of International Development, 11:1005-1027.

[9] Mahmoud Khosravi, Ali Akbar (2000), predicted household needs Sistan-Baluchistan, Sistan-Baluchestan Conference Proceedings, Tehran, Institute for Business Research, February 2000, pp. 286.

[10] Management and planning, detailed results of the survey of rural household income and expenditure, Tehran, Iran Statistical Center of years (1991-2003).

[11] McCulloch, N and M. Calandrino (2003). Vulnerability and Chronic Poverty in Rural Sichuan. World Development, 31(3): 611-628.

[12] Motevaseli ,Mahmoud Samadi , Saeed( 1999), in recognition of the economic aspects of poverty reduction policies, Economic Research Journal, fall, winter, Number 55, pp. 98-65.

[13] Nadrnan, Elias, Nataj Amir Gholami, Saeed. (2000), explore the living conditions of the urban province: Black Poverty Amidst the leaves, Economic Research Journal, Fall \& Winter, No. 57, pp. 187-161.

[14] Pajooyan, J (1994). poverty, poverty lines and poverty reduction, organization, management and planning, Proceedings of the issue of poverty and poverty groups, the first volume of Tehran and Planning Agency Documentation Centre - Economic and Publications, 1996, pp. 43-59.

[15] Parveen, Soheila( 1996)- Poverty alleviation in poverty schools at the Economic Research Council, in September and December quarters 1996, pp. 210-189.

[16] Poollak,R. A. and T.J. Walls( 1969), Estimation LES Econometrica,vol, o 4, pp

[17] Zhang, Y and G. Wan. (2006). An empirical analysis of household vulnerability in Rural China. Journal of the Asia Pacific Economy, 11(2): 196-212. 